\title{
HIDRÓLISE ENZIMÁTICA DA LACTOSE DE PERMEADO DE SORO
}

\section{Enzymatic hydrolysis of lactose of whey permeate}

Karina Nascimento de Almeida ${ }^{I}$, Tarso da Costa Alvim ${ }^{I}$, Adriana Régia Marques de Souza ${ }^{I}$, Gabriela Eustaquio Lacerda ${ }^{1}$, Fernanda Aparecida Lima Silva Alvim ${ }^{I}$, Jonas Chaves Alvim ${ }^{l}$

\section{RESUMO}

O permeado de soro é o resíduo do processo de concentração das proteínas do soro pelo método de ultrafiltração. Contém nutrientes importantes, como lactose, minerais e traços de proteínas e lipídeos. É um resíduo sem fim industrial estabelecido que causa sérios danos ao meio ambiente. Para que o seu aproveitamento seja integral e para permitir seu consumo por pessoas intolerantes ao açúcar do leite é preciso que a lactose seja hidrolisada. A hidrólise enzimática pela lactase ( $\beta$-galactosidase) do fungo Kluyveromyces lactis é um método seguro e que não compromete a integridade dos demais nutrientes, permitindo assim o posterior uso do permeado como matériaprima. Este trabalho objetivou realizar ensaios de hidrólise enzimática da lactose de formulações de permeado de soro, em concentração de $0,2 \%, 0,7 \%$ e $1 \%$ nos tempos 30,60 e 90 minutos com o $\mathrm{pH}$ do meio de 6,3 e temperatura de $37^{\circ} \mathrm{C}$. As reações foram acompanhadas por cromatografia líquida de alta eficiência que mostrou que a partir da concentração enzimática de $0,7 \%$ no tempo de 30 minutos, as formulações se tornaram seguras para o consumo de intolerantes à lactose, de acordo com níveis mínimos estabelecidos pela legislação.

Palavras-chave: intolerância à lactose; $\beta$-galactosidase; cromatografia líquida de alta eficiência.

\begin{abstract}
The whey permeate is the residual of the concentration process of the whey proteins by ultrafiltration method. It contains important nutrients such as lactose,
\end{abstract}

1 Fundação Universidade Federal do Tocantins (UFT), Campus Universitário de Palmas, avenida NS 15, ALC NO 14, 109 Norte, 77001-090, Palmas, TO, Brasil. E-mail: kna_engenharia@hotmail.com

* Autor para correspondência. 
minerals and some proteins and lipids. It is without an ending industrial waste that causes serious damage to the environment. For its full use the lactose must be hydrolyzed to enable its consumption by intolerant people. The enzymatic hydrolysis by lactase ( $\beta$-galactosidase) of Kluyveromyceslactis yeast is a safe method that does not compromise the integrity of other nutrients, enabling further use of the permeate as a raw material. This study aimed to perform tests of enzymatic hydrolysis of lactose in whey permeate formulations in a concentration of $0.2 \%, 0.7 \%$ and $1 \%$ at 30,60 and 90 minutes with pH 6.3 medium and $37^{\circ} \mathrm{C}$. The reactions were monitored by high performance liquid chromatography which showed that the enzyme concentration of $0.7 \%$ at time 30 minutes formulations became safe for consumption by lactose intolerant people, according to minimum levels established by law.

Keywords: lactose intolerance; $\beta$-galactosidase; high performance liquid chromatography.

\section{INTRODUÇÃO}

O permeado de soro (PS) é o resíduo do processo de concentração das proteínas do soro por ultrafiltração (UF), e contém nutrientes importantes, como lactose, minerais e pode conter traços de proteína e lipídeos (ZACARCHENCO et al., 2012). Em razão do alto conteúdo de nutrientes, o PS tem seu descarte no meio ambiente e assim como o soro, causam sérios danos ambientais (ELKHAIR, 2009) e seu aproveitamento evitaria aumento de custos nas estações de tratamento de efluentes (ZACARCHENCO et al., 2012). O PS contém em média $3 \%$ a $8 \%$ de proteínas de menor funcionalidade que as do soro, $68 \%$ a $85 \%$ de lactose, $8 \%$ a $20 \%$ de minerais (cinzas) e um conteúdo máximo de $1,5 \%$ de lipídeos (STOLlAR, 2009).

A lactose é o único carboidrato de origem animal na cadeia alimentar do homem. No intestino é hidrolisado pela enzima lactase para então ser absorvida como glicose e galactose. A intolerância é uma deficiência ou ausência na produção da lactase pelo organismo e este problema surge em maior ou menor intensidade em função de fatores como: idade ou etnia. No intestino inferior, a lactose não hidrolisada está sujeita a fermentação com distensão e desconforto associado, levando em alguns casos à diarreia (ZADOW, 1984).

A hidrólise da lactose pode ser realizada de duas maneiras, por via química ou enzimática. A hidrólise química é realizada em meio extremamente ácido com $\mathrm{pH}$ abaixo de 1,5 e temperatura elevada que chega até $150{ }^{\circ} \mathrm{C}$ (GÄNZLE et al., 2008). A hidrólise química possui desvantagens como condições operacionais rigorosas que causam a desnaturação protéica, há a necessidade de prévia desmineralização do meio devido à inativação do ácido na presença dos sais minerais, e, um outro fato é o aparecimento de uma cor castanha devido a reação de Maillard e a formação de produtos indesejáveis (SISO, 1996).

Na hidrólise enzimática, a enzima utilizada é a lactase ( $\beta$-galactosidase) que é encontrada em animais, plantas, bactérias, fungos e leveduras. A lactase hidrolisa a lactose, que é um dissacarídeo, nos componentes glicose e galactose, que são monossacarídeos. No entanto, as enzimas de estirpes consideradas seguras para o consumo humano são Kluyveromyces lactis, Kluyveromyces fragilis, Aspergillus niger e Aspergillus oryzae (SISO, 1996).

As enzimas obtidas de Kluyveromyces lactis têm pH ótimo de 6-7 e temperatura 
ótima de cerca de $35^{\circ} \mathrm{C}$. As enzimas de Kluyveromyces fragilis têm o $\mathrm{pH}$ ótimo de 6,5 e temperatura ótima de $40^{\circ} \mathrm{C}$. As enzimas a partir de fungos, tais como Aspergillus niger, têm o $\mathrm{pH}$ ótimo de 4,8 e temperatura ótima de $50{ }^{\circ} \mathrm{C}$ (ZADOW, 1984).

Para a detecção da lactose e de compostos gerados na hidrólise, um método instrumental de destaque é a cromatografia líquida de alta eficiência (CLAE) que tem a capacidade de separação de múltiplos compostos, apresentando exatidão e sensibilidade para pequenas quantidades amostras (COSTA, 2009).

O objetivo deste trabalho foi usar a CLAE para quantificar a lactose em formulações elaboradas de permeado de soro em pó reconstituído, acompanhando ensaios de hidrólise enzimática da lactose. Foram determinados parâmetros de concentração enzimática, tempo e temperatura mínimos e ideais para que o produto pudesse ser utilizado em alimentos, em níveis considerados seguros, para o consumo de pessoas intolerantes à lactose, conforme estabelecido pela legislação vigente.

\section{MATERIAL E MÉTODOS}

\section{Substrato}

O permeado de soro em pó foi adquirido da empresa Sooro Concentrado Indústria de Produtos Lácteos Ltda. O produto comercializado é obtido da ultrafiltração por membranas em que a proteína de soro é retirada e o permeado gerado é concentrado em evaporador a vácuo e seco por meio do processo tipo spray dryer. Em seguida, o produto foi acondicionado e comercializado em embalagens de $25 \mathrm{~kg}$. O produto é um pó uniforme e sem grumos, de sabor e odor lácteos, cor branca a amarelada e contém os parâmetros físico-químicos, nutricionais e microbiológicos fornecidos pela empresa (Tabela 1).
Tabela 1 - Parâmetros físicos, químicos, físico-químicos e nutricionais do permeado de soro em pó

\begin{tabular}{lc}
\hline \multicolumn{1}{c}{ Parâmetro } & Quantidade \\
\hline Umidade $(\%)$ & máx. 4 \\
Acidez titulável & máx. 2 \\
(\% ácido lático) & $6,0-6,7$ \\
pH & máx. 6 \\
Cinzas (\% resíduo & mín. 88 \\
mineral fixo) & máx. 3 \\
Lactose $(\%)$ & 429 \\
Proteína $(\%)$ & 490 \\
Sódio $(\mathrm{mg} / 100 \mathrm{~g})$ & Cálcio $(\mathrm{mg} / 100 \mathrm{~g})$
\end{tabular}

Fonte: empresa Sooro Conc. Ind. de Prod. Lácteos.

\section{Enzima}

A enzima utilizada foi a lactase $\beta$-galactosidase obtida do fungo Kluyveromyces lactis, nome comercial Maxilact ${ }^{\circledR}$ LX-5000, fabricada por DSM Food Specialties France, importada pela Global Food, São Paulo, Brasil.

\section{Reconstituição do permeado em pó}

O permeado de soro foi diluído em água destilada nas concentrações de forma que não houvesse formação de precipitado, ou seja, em que todo o conteúdo fosse dissolvido. Foram eleitas três concentrações para os ensaios de hidrólise (Tabela 2).

Tabela 2 - Concentração das formulações diluídas de permeado (em percentual)

\begin{tabular}{cc}
\hline Amostra & $\begin{array}{c}\text { Permeado } \\
(\mathrm{g} / 100 \mathrm{~mL})\end{array}$ \\
\hline 1 & 1,4 \\
2 & 2,0 \\
3 & 2,8 \\
\hline
\end{tabular}




\section{Análises físicas, químicas e físico-químicas}

Foram realizadas análises nas três formulações do permeado antes e depois da hidrólise. Foram aferidos e quantificados o $\mathrm{pH}$, utilizando medidor de $\mathrm{pH}$ de bancada previamente calibrado. O teor de sólidos totais ( $\left.{ }^{\circ} \mathrm{Brix}\right)$ foi determinado por refratômetro portátil com a amostra a $25^{\circ} \mathrm{C}$. O conteúdo protéico foi determinado pelo método de Kjeldahl e o de gordura pelo método de Gerber. O extrato seco foi determinado por evaporação da fração líquida em estufa a $105^{\circ} \mathrm{C}$ até massa constante e o teor de cinzas foi determinado por incineração da amostra seca em forno mufla a $550{ }^{\circ} \mathrm{C}$ por 5 horas (IAL, 2008). A quantificação dos minerais sódio e potássio foi determinada por fotômetro de chama Analyzer 910MS (KORZUN; MILLER, 1987).

\section{Quantificação do teor de lactose}

A quantificação da lactose e o acompanhamento das reações de hidrólise foram realizados por CLAE, em equipamento da marca Shimadzu (LC-10Series Avp; desgaseificador: DGU-14A, integrador: CLASS LC-10) com eluição isocrática, pelo bombeamento (LC-10AD) de uma fase móvel composta de $5 \mathrm{mM}$ de ácido sulfúrico em água ultrapura (destilada e deionizada). $\mathrm{O}$ fluxo do eluente foi de $0,6 \mathrm{~mL} / \mathrm{min}$ a $40{ }^{\circ} \mathrm{C}$ (forno de coluna CTO-10A), com corrida de tempo total de 20 minutos. Uma alíquota de aproximadamente $20,0 \mu \mathrm{L}$ de amostra foi injetada manualmente (injetor Rheodyne - IL malha 20) e permeada por uma coluna de fase reversa da marca Phenomenex Rezex ROA-Organic Acid H+ (300 x 7,8 mm) com conexão direta a cartucho de segurança Phenomenex Carbo-H (4 x $3 \mathrm{~mm}$ ), preenchida com material semelhante ao da coluna principal. A detecção foi feita em detector de índice de refração (Shimadzu, modelo RID-10A).
Para a quantificação da lactose foi preparada uma solução padrão e injetada nas mesmas condições da amostra, em diferentes concentrações $(0,125 \mathrm{mg} / \mathrm{mL} ; 0,25 \mathrm{mg} / \mathrm{mL}$; $0,5 \mathrm{mg} / \mathrm{mL} ; 0,75 \mathrm{mg} / \mathrm{mL}$ e $1 \mathrm{mg} / \mathrm{mL}$ ) para a construção da curva analítica e obtenção da equação da reta utilizada para calcular a concentração por meio da área do pico fornecida pelo equipamento.

\section{Ensaio de hidrólise da lactose com permeado}

Os parâmetros determinantes na hidrólise foram $\mathrm{pH}$ do meio, concentração da enzima e tempo de hidrólise. $\mathrm{O} \mathrm{pH}$ das formulações de permeado 1, 2 e 3 estavam dentro da faixa ótima de atividade da enzima ( $\mathrm{pH}$ 6-7). Foram realizados ensaios com concentrações de enzima de $0,2 \% ; 0,7 \%$ e $1 \%$ nos tempos 30, 60 e 90 minutos, a $37^{\circ} \mathrm{C}$, em banho-maria termostatizado (CASTRO, 2011). As amostras foram retiradas do banho no momento determinado, refrigeradas a $5^{\circ} \mathrm{C}$ e, em seguida, filtrada em membrana millipore $0,45 \mu \mathrm{m}$ e analisada por CLAE para acompanhamento do processo de hidrólise da lactose.

\section{Análise estatística}

As análises físicas, químicas e físicoquímicas foram realizadas em duas repetições e os resultados analisados por análise de variância (ANOVA) em delineamento inteiramente casualizado com avaliação das médias por teste de Tukey a 5\% de significância pelo software ASSISTAT ${ }^{\circledR}$ versão 7.7 beta (SILVA; AZEVEDO, 2009).

\section{RESULTADOS E DISCUSSÃO}

\section{Análises físicas, químicas e físico-químicas}

A Tabela 3 apresenta os resultados das análises físicas e químicas das formulações de permeado diluído (P) e hidrolisado (P. Hidro.). 
Em todas as formulações não houve percentual para gordura, quantificando-se em $0 \%$. O pH nas formulações de P e P. Hidro. se manteve em 6,3 que é um fator determinante para a atividade enzimática, permanecendo na faixa ótima.

O teor de sólidos solúveis pode ser determinado indiretamente por refratometria por serem aproximadamente iguais. A exemplo, o índice de refração de uma solução de sacarose é uma medida de teor de sacarose e o seu conceito é estendido para indicar sólidos solúveis ou Brix em soluções impuras que é denominado Brix refratométrico. A escala Brix é calibrada pelo número de gramas de açúcar contidos em $100 \mathrm{~g}$ de solução (SANTOS et al., 2013). Nos resultados apresentados foi possível observar um relativo aumento no ${ }^{\circ} \mathrm{Brix}$ entre as formulações de P e P. Hidro., que é justificado pela adição da enzima usada no processo de hidrólise e transformação de lactose em glicose e galactose. Tanto P quanto P. Hidro. apresentaram diferença estatística significativa $(\mathrm{p}<0,05)$, porém, quando analisadas entre os tratamentos, as amostras 3 (P e P. Hidro.) se apresentam estatisticamente iguais $(\mathrm{p}>0,05)$. Como essa foi a formulação com maior percentual de permeado, e consequentemente de lactose, e a concentração enzimática e tempo de hidrólise foram semelhantes nas três formulações, a formulação mais concentrada poderá ter um menor percentual de hidrólise.

Teores proteicos de até 3\% condizem com o indicado pelo fornecedor do PS em pó. Andrade; Martins (2002) analisaram o conteúdo protéico de PS líquido e obtiveram resultados entre 0,5-1\%. Nas formulações desenvolvidas foi possível observar considerável aumento no teor proteico entre P e P. Hidro., o que é justificado pela adição da enzima. Estatisticamente, todas as formulações apresentaram diferenças $(\mathrm{p}<0,05)$ para as formulações do mesmo tratamento e entre tratamentos.

O extrato seco total representa o conteúdo de sólido presente nas amostras e as cinzas, a substância inorgânica (IAL, 2008). O conteúdo de extrato seco total apresentou diferença estatística significativa $(\mathrm{p}<0,05)$ entre as etapas de P e P. Hidro., evidenciado pela adição da enzima e pelos produtos da

Tabela 3 - Resultados das análises físicas, químicas e físico-químicas das formulações de permeado (P) e permeado hidrolisado (P. Hidro.)

\begin{tabular}{|c|c|c|c|c|c|c|c|}
\hline & Amostra & $\begin{array}{l}{ }^{\circ} \text { Brix } \\
(\mathrm{m} / \mathrm{m})\end{array}$ & $\begin{array}{c}\text { Proteína } \\
(\%) \\
(\mathrm{m} / \mathrm{v})\end{array}$ & $\begin{array}{c}\text { Extrato } \\
\text { seco total } \\
(\mathrm{m} / \mathrm{m})(\%)\end{array}$ & $\begin{array}{c}\text { Cinzas } \\
(\mathrm{m} / \mathrm{m})\end{array}$ & $\begin{array}{l}\text { Sódio } \\
(\mathrm{ppm})\end{array}$ & $\begin{array}{c}\text { Potássio } \\
\text { (ppm) }\end{array}$ \\
\hline \multirow{3}{*}{$a$} & 1 & $1,4^{\mathrm{C} \mathrm{b}}$ & $0,42^{\mathrm{Cb}}$ & $1,2991^{\mathrm{Cb}}$ & $0,0839^{\mathrm{B} \mathrm{a}}$ & $93^{\mathrm{Ba}}$ & $180^{\mathrm{B} \mathrm{b}}$ \\
\hline & 2 & $2,0^{\mathrm{B} \mathrm{b}}$ & $0,56^{\mathrm{B} \mathrm{b}}$ & $* 1,9328^{\text {в b }}$ & $* 0,1150^{\text {В b }}$ & $140^{\mathrm{Aa}}$ & $303^{\mathrm{Aa}}$ \\
\hline & 3 & $2,9^{\mathrm{Aa}}$ & $0,68^{\mathrm{Ab}}$ & $2,5528^{\mathrm{Ab}}$ & $0,1502^{\mathrm{Aa}}$ & $153^{\mathrm{Aa}}$ & $333^{\mathrm{Aa}}$ \\
\hline \multirow{3}{*}{ 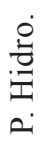 } & 1 & $2,0^{\mathrm{Ca}}$ & $0,66^{\text {Ca }}$ & $1,5057^{\mathrm{Ca}}$ & $0,0911^{\mathrm{Ca}}$ & $70^{\mathrm{Cb}}$ & $213^{\mathrm{Ca}}$ \\
\hline & 2 & $2,5^{\mathrm{B} \mathrm{a}}$ & $0,79^{\mathrm{B} \mathrm{a}}$ & $* 2,1673^{\text {В а }}$ & $* 0,1363^{\text {В а }}$ & $120^{\mathrm{B} \mathrm{b}}$ & $306^{\mathrm{B} \text { a }}$ \\
\hline & 3 & $3,0^{\mathrm{A} a}$ & $0,97^{\mathrm{A} \mathrm{a}}$ & $2,7201^{\mathrm{Aa}}$ & $0,1475^{\text {A a }}$ & $160^{\mathrm{Aa}}$ & $393^{\mathrm{Aa}}$ \\
\hline
\end{tabular}

${ }^{1}$ Amostra 1, 2, 3 representam respectivamente $1,4 \mathrm{~g}$ permeado/100ml, 2,0g permeado/100ml e $2,8 \mathrm{~g}$ permeado/100ml. ${ }^{2} \mathrm{P}$ : Permeado diluído. ${ }^{3} \mathrm{P}$. Hidro.: Permeado hidrolisado na concentração enzimática de $0,7 \%$ a $37{ }^{\circ} \mathrm{C}$, por 60 minutos. ${ }^{4}$ Letras maiúsculas: Teste de média entre formulações de mesma etapa (P/P. Hidro.).

${ }^{5}$ Letras minúsculas: Teste de média entre formulações de etapas diferentes (1P/1P. Hidro.; 2P/2P. Hidro. e 3P/3P. Hidro.). ${ }^{6}$ Letras iguais não apresentam diferença significativa ao nível de $5 \%$ de significância pelo teste de Tukey. ${ }^{7 *}$ Dados transformados para adequação à normalidade. 
hidrólise. A formulação 2 apresentou maior diferença, refletindo no conteúdo de cinzas que apresentou diferença estatística significativa ( $\mathrm{p}$ $<0,05)$ entre as etapas de P e P. Hidro.

Os conteúdos de sódio e potássio foram expressivos nas formulações de permeado. Estes minerais participam da atividade enzimática da lactase como cofatores (DICKSON et al., 1979) refletindo em alterações dos teores após a etapa de hidrólise.

\section{Determinação de lactose por CLAE}

\section{Curva padrão de lactose}

Foi possível obter a equação da reta (Tabela 4) usada para quantificar o conteúdo de lactose pela substituição da área do pico pela variável Y (Figura 1).

Tabela 4 - Dados da curva padrão de lactose determinada por CLAE

\begin{tabular}{ccc}
\hline $\begin{array}{c}\text { Concentração } \\
(\mu \mathrm{g} / \mathrm{mL})\end{array}$ & $\begin{array}{c}\text { Tempo de } \\
\text { retenção }(\mathrm{min})\end{array}$ & $\begin{array}{c}\text { Área do } \\
\text { Pico }\end{array}$ \\
\hline 125 & 9,20 & 31319 \\
250 & 9,17 & 65864 \\
500 & 9,34 & 130699 \\
750 & 9,525 & 223515 \\
1000 & 9,67 & 299022 \\
\hline
\end{tabular}

\section{Quantificação de lactose no permeado}

As três amostras foram injetadas no equipamento de forma diluída para que o pico se mantivesse dentro da concentração da curva padrão, cujos valores da concentração de lactose nas formulações de permeado foram corrigidas pelo fator de diluição (Tabela 5).

Tabela 5 - Concentração de lactose nas formulações de permeado

\begin{tabular}{cc}
\hline Permeado & $\begin{array}{c}\text { Concentração } \\
(\mathrm{g} / 100 \mathrm{~mL})\end{array}$ \\
\hline 1 & 1,0195 \\
2 & 2,5532 \\
3 & 7,4943 \\
\hline
\end{tabular}

\section{Ensaios de hidrólise da lactose com permeado}

A Portaria 29/98 (ANVISA, 1998) determina que $0,5 \%$ é considerado um nível seguro de lactose para a ingestão por pessoas com intolerância a este nutriente. Ou seja, qualquer área do pico referente à lactose que se apresentar abaixo da área da curva padrão da concentração de $500 \mu \mathrm{g} / \mathrm{ml}$ (que representa $0,5 \mathrm{~g}$ de lactose em $100 \mathrm{~mL}$ de permeado) é

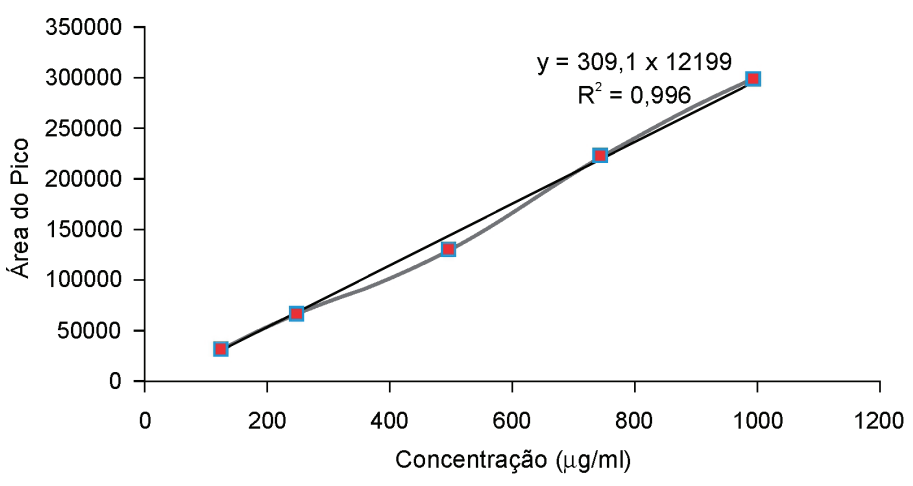

Figura 1 - Curva padrão de lactose determinada por CLAE 
considerada apta para o consumo por sujeitos intolerantes a esse açúcar.

A relação entre a área do pico, a concentração enzimática e o tempo de hidrólise da formulação 3 (que é a formulação mais concentrada em lactose) garante que a hidrólise das formulações de menor concentração de lactose também tenha sido hidrolisada a níveis seguros (Figura 2). A partir da relação concentração enzimática de $0,7 \% / 30$ minutos já foi possível visualizar que a área do pico estava abaixo do nível considerado seguro para o consumo das formulações apresentadas. Os ensaios que seguem $0,7 \% / 60$ minutos; $0,7 \% / 90$ minutos; $1 \% / 30$ minutos; $1 \% / 60$ minutos e $1 \% / 90$ minutos também alcançaram a taxa de hidrólise desejada, porém, evidenciam um maior consumo de tempo ou enzima.

Castro et al. (2011) realizaram ensaios de hidrólise da lactose de soro de queijo com a lactase $\beta$-galactosidase de $K$. lactis (Maxilact $^{\circledR}$ LX-5000) e verificaram que os maiores pontos de hidrólise da lactose foram obtidos nas concentrações enzimáticas de $0,2 \%(\mathrm{~m} / \mathrm{v})$ e $0,7 \%(\mathrm{~m} / \mathrm{v})$ a temperatura de $37^{\circ} \mathrm{C}$ e pH 6,5 por 50 minutos.

Vieira (2006) realizou ensaios enzimáticos com a lactase ( $\beta$-galactosidase) de K. lactis da marca Prozin ${ }^{\circledR}$ em soro em pó reconstituído com concentração de lactose de $75 \%$, mantendo a concentração de $0,4 \%$ nas temperaturas de $43{ }^{\circ} \mathrm{C}, 45{ }^{\circ} \mathrm{C}, 48{ }^{\circ} \mathrm{C}$ e $53{ }^{\circ} \mathrm{C}$ nos pH 6,0 e 6,5. Os melhores pontos de conversão foram apresentados na temperatura de $45{ }^{\circ} \mathrm{C}$, no $\mathrm{pH} 6,5$ o tempo foi de 45 minutos e no $\mathrm{pH}$ de 6,0 em 60 minutos.

Andrade et al. (2004) utilizaram enzima Maxilact ${ }^{\circledR}$ LX-5000 para a lactose de leite com o objetivo de formular sorvete com lactose hidrolisada e obtiveram melhor ponto de hidrólise com concentração de $0,2 \%$, com $37^{\circ} \mathrm{C}$, porém com 5 horas.

Carminatti (2001) realizou ensaios com lactase ( $\beta$-galactosidase) também de $K$. lactis (Maxilact $^{\circledR}$ L-5000) avaliando temperatura, $\mathrm{pH}$ e concentração enzimática. Para avaliar a melhor temperatura trabalhou nas faixas de $30{ }^{\circ} \mathrm{C}, 35^{\circ} \mathrm{C}, 40{ }^{\circ} \mathrm{C}, 45^{\circ} \mathrm{C}$ e $50{ }^{\circ} \mathrm{C}$ com pH 6 e concentração enzimática de $0,125 \%$ constantes. Para avaliar o $\mathrm{pH}$ com temperatura de $40{ }^{\circ} \mathrm{C}$ e concentração enzimática $0,125 \%$ constantes, as variações ocorreram nos valores de $\mathrm{pH}$ de 4, 5, 6 e 7. Para avaliar as concentrações enzimáticas usou $0,04 \%$, $0,125 \%$ e $0,2 \%$ com $\mathrm{pH} 6$ e temperatura de $40{ }^{\circ} \mathrm{C}$ constantes, os tempos de hidrólise chegaram a 4 horas. Este autor notou que em temperaturas acima de $40{ }^{\circ} \mathrm{C}$ a conversão da

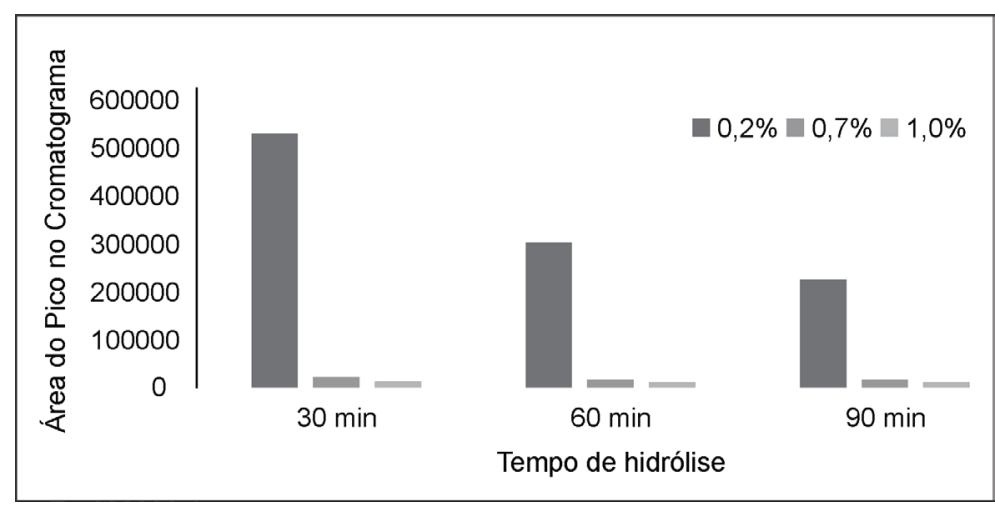

Figura 2 - Relação entre a área do pico, a concentração enzimática e o tempo de hidrólise da formulação 3 
lactose foi reduzida e que a conversão se mantém constante após atingir o ponto máximo. A faixa de $\mathrm{pH}$ ótima se manteve entre 6-7, e no $\mathrm{pH} 4$ a conversão foi zero e em $\mathrm{pH} 5$ foi de $1 \%$. As condições ótimas eleitas pelo autor para este ensaio enzimático foram a $30^{\circ} \mathrm{C}, \mathrm{pH} 6 \mathrm{e}$ concentração enzimática de $0,125 \%$.

\section{CONCLUSÕES}

A hidrólise da lactose do permeado de soro formulado nas concentrações enzimáticas de $0,7 \%$ e $1 \%$, ambas a $37^{\circ} \mathrm{C}$ por 30,60 e 90 minutos garantem que a lactose das três formulações de permeado de soro sejam hidrolisadas a níveis seguros para o consumo de pessoas com intolerância a esse nutriente.

É importante ressaltar que há diferentes tipos de lactase no mercado, de diferentes microrganismos, que possuem $\mathrm{pH}$, tempo e concentrações diferentes de atuação. Também deve ser levado em consideração a composição do produto a ser hidrolisado e a forma que os componentes interferem ou não na disponibilidade do substrato lactose, em relação à enzima.

\section{AGRADECIMENTOS}

A Coordenação de Aperfeiçoamento de Pessoal de Nível Superior - CAPES pela Bolsa concedida.

\section{REFERÊNCIAS}

AGÊNCIA NACIONAL DE VIGILÂNCIA SANITÁRIA (ANVISA). Portaria n ${ }^{\circ} 29$, de 13 de janeiro de 1998. Aprova o Regulamento Técnico referente a Alimentos para Fins Especiais. Diário Oficial da República Federativa do Brasil, Brasília, 30 mar. 1998.

ANDRADE, V. T. et al. Sorvete de doce de leite delactosado. Revista do Instituto de Laticínios Cândido Tostes, v. 59, n. 339, p. 126-130, 2004.
ANDRADE, R. L. P.; MARTINS, J. F. P. Influência da adição da fécula de batata-doce (Ipomoea Batatas L.) sobre a viscosidade do permeado de soro de queijo. Ciência e Tecnologia de Alimentos, v. 22, n. 3, p. 249-253, 2002.

CARMINATTI, C. A. Ensaios de hidrólise enzimática da lactose em reator a membrana utilizando beta-galactosidase e Kluyveromyces lactis. 2001. 79f. Dissertação (Mestrado em Engenharia Química) - Universidade Federal de Santa Catarina, Florianópolis, 2001 .

CASTRO, I. P. M. et al. Efeito da adição de soro de queijo no processo de obtenção de etanol a partir de batata-doce. Ciência e Agrotecnologia, v. 35, n. 5, p. 980-986, 2011.

COSTA, A. L. O. Éster 2-morfolinoetil e sal sódico do ácido micofenólico: desenvolvimento e validação de métodos analíticos para o controle de qualidade de matériaprima e comprimidos. 2009. 219f. Dissertação (Mestrado em Ciências Farmacêuticas) Universidade Federal de Minas Gerais, Belo Horizonte, 2009.

DICKSON, R. C. et al. Purification and properties os an inducible $\beta$-galactosidase isolated from the yeast Kluyveromyces lactis. Journal of Bacteriology, v. 137, n. 1, p. 5161, 1979.

EL-KHAIR, A. A. A. Formulation of milk permeate for utilization as electrolyte beverages. Australian Journal of Basic and Applied Sciences, v. 3, n. 2, p. 572-578, 2009.

GÄNZLE, M. G. et al. Lactose: crystallization, hydrolysis and value-added derivatives. International Dairy Journal, v. 18, n. 7, p. 685-694, 2008. 
INSTITUTO ADOLFO LUTZ. Métodos físico-químicos para análise de alimentos. 4 ed., 1 ed. digital. São Paulo: Instituto Adolfo Lutz, 2008. 1020 p. Disponível em: <http:// www.ial.sp.gov.br/index.php $>$ Acesso em: 12 maio 2013.

KORZUN, W. J., MILLER, W. G. Sodium and potassium. In: PESCE, A. J., KAPLAN, L. A. Methods in clinical chemistry. Saint Louis: Mosby, 1987. p. 86-91.

SANTOS, A. H. et al. Metodologia do ensino de química. Minicurso-você sabe o que está comendo? Entenda a composição química dos alimentos! Universidade de São Paulo-USP. 2013. Disponível em: <http:// www.lapeq.fe.usp.br/minicurso/mc2013/pdf/ minicurso_2013_vesp_03_alimentacao.pdf $>$ Acesso em: 12 jun. 2014.

SILVA, F. A. S. E.; AZEVEDO, C. A. V. Principal components analysis in the software assistat-statistical attendance. In: WORLD CONGRESS ON COMPUTERS IN AGRICUlTURE, 7., 2009. Proceedings...
Reno-NV-USA: American Society of Agricultural and Biological Engineers, 2009.

SISO, M. I. G. The biotechnological utilization of cheese whey: a review. Bioresource Technology, v. 57, n. 1, p. 1-11, 1996.

STOLIAR, M. U. S. Whey ingredients in bakery products. 2009. 8 p. U.S. Dairy Export Council $^{\circledR}$ (USDEC Monography) - Arlington, 2009.

VIEIRA, A. A. M. T. Estudo da hidrólise enzimática do soro de queijo utilizando as lactases Lactozym ${ }^{\circledR}$ e Prozyn ${ }^{\circledR}$. 2006. 77f. Dissertação (Mestrado em Engenharia Química) - Universidade Federal de Uberlândia, Uberlândia, 2006.

ZACARCHENCO, P. B. et al. Permeado de soro: Aplicações que agregam valor aos coprodutos do leite. Anuário Leite e Derivados, v. 23, n. 131, p. 48-55, 2012.

ZADOW, J. G. Lactose: Properties and uses. Journal of Dairy Science, v. 67, n. 11, p. 2654-2679, 1984. 